\title{
Breast cancer awareness in the sub-Saharan African ABC-DO cohort: African Breast Cancer-Disparities in Outcomes study
}

\author{
Fiona McKenzie ${ }^{1}$ (1) Annelle Zietsman ${ }^{2} \cdot$ Moses Galukande $^{3} \cdot$ Angelica Anele $^{4} \cdot$ Charles Adisa $^{5} \cdot$ Groesbeck Parham $^{6}$. \\ Leeya Pinder ${ }^{6} \cdot$ Isabel dos Santos Silva $^{7} \cdot$ Valerie McCormack $^{1}$
}

Received: 1 December 2017 / Accepted: 2 June 2018 / Published online: 6 July 2018

\begin{abstract}
A greater understanding of the nature and drivers of poor breast cancer (BC) awareness in sub-Saharan Africa (SSA) will inform much needed awareness programmes. We aimed to assess the level and nature of $\mathrm{BC}$ awareness in the multi-country African Breast Cancer-Disparities in Outcome (ABC-DO) cohort of women newly diagnosed with BC during 2014-2017. Awareness indicators were assessed during a baseline interview at/near diagnosis. Logistic/ordinal regression was used to estimate odds ratios (OR) for indicators of $\mathrm{BC}$ awareness in relation to woman-level characteristics for individual settings and then meta-analyzed. In the 1,451 women included, almost all Namibian non-black women $(n=104) \mathrm{knew}$ of BC and its curability, while in Namibian black and Zambian women, one in $7(\sim 15 \%)$ had not previously heard of BC and 25-40\% did not know it was curable. In Uganda and Nigeria awareness was lowest: one in four women had no BC awareness, and 2 in 3 had no knowledge of its cure potential. Low educational level, unskilled employment, low socioeconomic position, rural residence, older age, being unmarried, and in some settings HIV-positivity, were associated with lower BC awareness-e.g., having unskilled employment was associated with not having heard of BC (summary OR 3.37; 95\% confidence interval (CI) 2.17-5.23), believing that it is incurable $(2.43 ; 1.81-3.26)$, and not recognizing a breast lump symptom $(1.85 ; 1.41-2.43)$ but with between-setting variation $\left(I^{2}>68 \%\right.$ for all). The findings provide evidence of the level and difference in BC awareness and beliefs across different settings, highlighting the urgent need for context-specific education programmes in the SSA region.
\end{abstract}

Keywords Breast cancer $\cdot$ Awareness $\cdot$ Beliefs $\cdot$ Symptoms $\cdot$ Sub-Saharan Africa

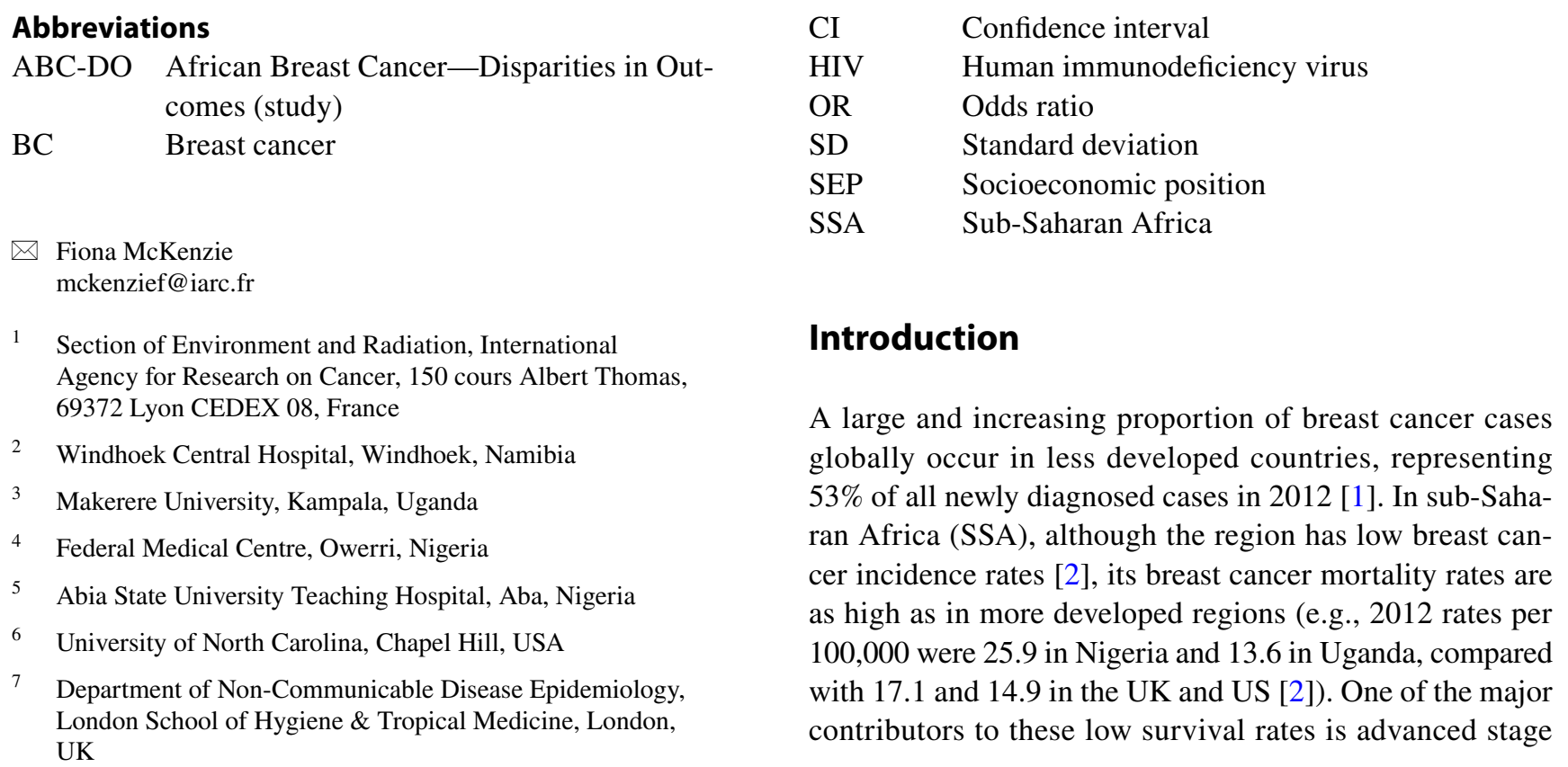


at breast cancer diagnosis; in individual settings, between 55 and $80 \%$ are diagnosed at stages III/IV [3], resulting from delays to presentation and diagnosis. At the start of this journey, the period between onset of symptoms and subsequent help-seeking actions provides a critical time window of opportunity for achieving earlier diagnosis [4, 5]. In order to seek help, patients must go through the threephase process of symptom appraisal. Firstly, a woman must notice her breast-related symptoms and signs; secondly, she must interpret these as being consistent with breast cancer or other breast health problem requiring attention; and, finally, she must seek appropriate healthcare [5]. This symptom appraisal process is influenced by a woman's awareness of breast cancer, including her familiarity with the disease, perception of risk of developing it, as well as recognition of its symptoms and knowledge of its potential to be successfully treated.

Breast cancer awareness is poor across many SSA settings [6-14]; partly due to this non-communicable disease historically not being a major health priority, at the individual level or for health campaigns. Additionally, the unique sociocultural characteristics and belief systems prevalent in the region, including low levels of education particularly in women, beliefs in witchcraft, fatalism, and spiritual causation, may influence awareness [15]. A better understanding of the nature of and likely drivers of poor breast cancer awareness in SSA will provide the evidence-base to inform much needed awareness programmes specifically tailored to target groups of women in the region [16].

The African Breast Cancer-Disparities in Outcome (ABC-DO) study is a large $(>2,100)$ breast cancer cohort in SSA [17]. In recent analyses of drivers of advanced stage at diagnosis, women were 1.6 times more likely to be diagnosed with advanced stage if they had never previously heard of breast cancer [18]. The objective of the current analysis was to assess the level and nature of breast cancer awareness in SSA, benefiting from a common methodology used in diverse settings and population groups.

\section{Methods}

\section{Study design and participants}

Levels of and factors associated with breast cancer awareness were examined in women diagnosed within the ABCDO study, a prospective multi-centric hospital-based study of survival after breast cancer diagnosis in SSA. The study settings included in the present analysis are primarily public hospitals: Windhoek Central Hospital, Namibia; Mulago Hospital and the Uganda Cancer Institute, Kampala, Uganda; Abia State University Teaching Hospital and the Maranatha private clinic, Aba and the Federal Medical
Centre, Owerri, Nigeria; and the Cancer Diseases Hospital and University Teaching Hospital, Lusaka, Zambia. The ABC-DO site in Soweto, South Africa, was not included in the present analysis as awareness questions differed. The ABC-DO protocol has been published in detail previously [17]. In brief, women aged 18 years or older who presented at the participating hospitals with a new clinical or histocytological diagnosis of primary breast cancer were invited to participate. Recruitment was over an approximate 2-year period at each site although dates varied between sites ( 01 September 2014 to 30 September 2017).

A response rate of $99 \%$ was achieved across sites. ABCDO was approved by ethics committees at each recruitment institution Federal Medical Center Owerri, Abia State University Teaching Hospital, University of Zambia Biomedical Research Ethics Committee (004-08-15), Uganda National Council for Science and Technology (HS 1588) and the Ministry of Health and Social Services of Namibia (17/3/3), the International Agency for Research on Cancer (IEC 13-19), and the London School of Hygiene and Tropical Medicine (6459). Women provided written informed consent, or a fingerprint as an alternative.

\section{Baseline questionnaire}

A face-to-face baseline questionnaire was used to gather socioeconomic, medical, and breast cancer awareness information at, or near, the time of diagnosis. Relationship status was ascertained and defined as currently married or not. Education was ascertained and defined as secondary or higher (secondary/technical/university) and primary or less (none/primary). Employment was defined as skilled (highly skilled/skilled) or unskilled (unskilled/not applicable). A score for socioeconomic position (SEP) was constructed from combining self-reported possessions and facilities: home ownership; indoor water; flush toilet; electricity; vehicle; refrigerator; landline; gas or electric stove; and a bed (range 1-10 and then reversed scored 9-0 for analysis). Usual place of residence was defined as urban (city/ town) or rural (village/rural). Self-reported comorbidities included selected health problems (listed in Table 1) and HIV infection, which is endemic in SSA; thus HIV-positive breast cancer patients are a new and rapidly growing patient population. HIV-positive women may have lower breast cancer awareness due to lower educational levels, and if so, improving awareness in this population group would be key as early diagnosis is one important action needed to improve poor prognosis for these women. On the other hand, the contact of a HIV-positive woman with the health system upon receipt of antiretrovirals is an opportunity for education, thus it could be possible that this population group may have greater breast cancer awareness than the general population. 
Table 1 Distribution of characteristics of ABC-DO breast cancer patients at diagnosis by population group

\begin{tabular}{|c|c|c|c|c|c|c|}
\hline \multirow[t]{4}{*}{ Characteristic } & \multicolumn{6}{|c|}{ Population group } \\
\hline & Zambia & Uganda & Nigeria & Namibia & Namibia non-Black ${ }^{\mathrm{a}}$ & Namibia non-Black $^{\mathrm{a}}$ \\
\hline & $n=123$ & $n=428$ & $n=398$ & $n=398$ & $n=104$ & $n=1,451$ \\
\hline & $N(\%)^{\mathrm{b}}$ & $N(\%)^{\mathrm{b}}$ & $N(\%)^{\mathrm{b}}$ & $N(\%)^{\mathrm{b}}$ & $N(\%)^{\mathrm{b}}$ & $N(\%)^{\mathrm{b}}$ \\
\hline \multicolumn{7}{|l|}{ Breast cancer-related } \\
\hline Age (years): mean (SD) & $51(16)$ & $48(13)$ & $49(12)$ & $53(15)$ & $57(12)$ & $51(14)$ \\
\hline BMI $\left(\mathrm{kg} / \mathrm{m}^{2}\right):$ mean $(\mathrm{SD})$ & $26(6)$ & $26(5)$ & $26(6)$ & $26(7)$ & $29(7)$ & $26(6)$ \\
\hline Nulliparous & $7(6)$ & $29(7)$ & $71(18)$ & $28(7)$ & $7(7)$ & $142(10)$ \\
\hline Family history BC & $4(4)$ & $24(6)$ & $21(6)$ & $67(17)$ & $29(28)$ & $145(11)$ \\
\hline Personal history BC & $3(3)$ & $9(2)$ & $11(3)$ & $6(2)$ & $6(6)$ & $35(3)$ \\
\hline Late stage at diagnosis ${ }^{c}$ & $62(50)$ & $248(58)$ & $268(67)$ & $255(64)$ & $26(25)$ & $859(59)$ \\
\hline \multicolumn{7}{|l|}{ Socio-demographic } \\
\hline Currently not married & $53(43)$ & $226(53)$ & $133(33)$ & $271(68)$ & $44(42)$ & $727(50)$ \\
\hline Rural residence & $42(34)$ & $321(75)$ & $144(36)$ & $174(44)$ & $11(11)$ & $692(48)$ \\
\hline \multicolumn{7}{|l|}{ Religion $^{\mathrm{d}}$} \\
\hline Christian & $122(99)$ & $355(83)$ & $394(99)$ & $378(95)$ & $101(97)$ & $1,350(93)$ \\
\hline Muslim & $1(1)$ & $57(13)$ & - & - & - & $58(4)$ \\
\hline \multicolumn{7}{|l|}{ Socioeconomic-related } \\
\hline Not literate in English ${ }^{\mathrm{e}}$ & $30(24)$ & $212(50)$ & $118(30)$ & $223(56)$ & $11(11)$ & $594(41)$ \\
\hline Not literate in mother tongue ${ }^{\mathrm{e}}$ & $22(18)$ & $100(23)$ & $189(47)$ & $66(17)$ & - & $377(26)$ \\
\hline Primary or no education & $70(57)$ & $247(58)$ & $108(27)$ & $209(53)$ & $13(13)$ & $647(45)$ \\
\hline Unskilled employment & $99(80)$ & $326(76)$ & $263(66)$ & $294(75)$ & $33(32)$ & $1,015(70)$ \\
\hline SEP score: mean $(\mathrm{SD})^{\mathrm{f}}$ & $4.6(1.9)$ & $3.6(1.4)$ & $5.3(1.3)$ & $5.1(2.2)$ & $7.4(1.0)$ & $4.8(1.9)$ \\
\hline \multicolumn{7}{|l|}{ Medical } \\
\hline HIV positive & $19(15)$ & $47(11)$ & $11(3)$ & $53(13)$ & $3(3)$ & $133(9)$ \\
\hline Has one or more comorbidity ${ }^{\mathrm{g}}$ & $53(43)$ & $171(40)$ & $305(77)$ & $239(60)$ & $70(67)$ & $838(58)$ \\
\hline \multicolumn{7}{|l|}{ Belief in } \\
\hline Orthodox medicine & $123(100)$ & $389(91)$ & $395(99)$ & $366(99)$ & $98(100)$ & $1,371(97)$ \\
\hline Traditional medicine & $45(37)$ & $164(38)$ & $90(23)$ & $56(15)$ & $7(7)$ & $362(26)$ \\
\hline Spiritual medicine & $115(94)$ & $206(48)$ & 307 (77) & $297(80)$ & $70(71)$ & 995 (70) \\
\hline
\end{tabular}

$B C$ breast cancer, $H I V$ human immunodeficiency virus, $S D$ standard deviation, $S E P$ socioeconomic position

${ }^{a}$ Non-Black group included white $(n=66)$ and colored women with mixed European/African or Asian ancestry $(n=38)$

${ }^{\mathrm{b}}$ Unless otherwise specified

${ }^{\mathrm{c}}$ Assessed using the American Joint Committee on Cancer TNM staging system, and further categorized as early (0-II) and late (III-IV) from known clinical data percentages among non-missing (6\% women with missing stage ranged from $0 \%$ in Namibia Black and non-Black to $14 \%$ in Zambia)

${ }^{\mathrm{d}}$ Other religions included Jehovah $(n=13)$, Pentecostal $(n=5)$, Adventist $(n=11)$, Traditional $(n=4)$, and no religion $(n=6)$

${ }^{\mathrm{e}}$ Read and write

${ }^{\text {f }}$ SEP score range (0-9 highest)

${ }^{g}$ Comorbidities (ever): high blood pressure/hypertension, heart disease, diabetes, anemia, COPD/chronic bronchitis/emphysema, asthma, hepatitis $\mathrm{B}$ or $\mathrm{C}, \mathrm{TB}$, other chronic infection, other cancer, other disease

Questions relating to breast cancer awareness included whether or not the woman had ever heard of this disease and the source(s) of this information (e.g., radio, family); whether she thought it was curable; and what factors she believed could cause breast cancer, which included commonly recognized established risk factors (i.e., increasing age, family history, and lifestyle) [19, 20], incorrect misconceptions (i.e., breast injury, infection, keeping money in the bra, curse, or spiritual attack) [21, 22], and a free text field of causes specified by the woman. In addition, questions were asked regarding her first symptom(s) and how she interpreted them at the time. Women were further asked whether they believed in orthodox, traditional, and spiritual medicine or healing. 


\section{Statistical methods}

Descriptive statistics are provided by population group which were defined based on country and additionally in Namibia by Black/non-Black ethnic group as these groups had stark differences in stage distributions and socioeconomic profiles [18]. Logistic regression models were used to estimate associations between woman-level characteristics and three indicators of poor breast cancer awareness-i.e., not having previously heard of breast cancer, believing breast cancer is incurable, and not recognizing their symptom (a lump or thickening of the area of the breast) as a breast lump or potential cancer. In addition, ordinal logistic regression was used to estimate associations with poorer knowledge of three breast cancer risk factors (i.e., aging, family history, lifestyle), which were coded into four levels, 0 through 3 , for knowledge of none (3), one (2), two (1), or three risk factors (0). This ordinal model maximizes the information provided and assumes a common odds ratio (OR) and 95\% confidence interval (CI) for each ordered dichotomy. Ageadjusted (in 10 year bands) ORs were estimated separately for each population group; random-effects meta-analysis was then used to examine between-population group heterogeneity in the magnitude and direction of the OR estimates and to yield a summary OR estimate. The primary results presented are age-adjusted only, as the identification of target groups with low awareness, rather than causal drivers, was considered the most useful for public health needs at present. Selected mutually adjusted ORs are provided in the text. In instances when there was no variance in the awareness indicator or exposures among a population group, this group was excluded.

All analyses were performed using STATA version 14.2. All $p$ values are two-sided.

\section{Results}

\section{Characteristics of the participants}

In all, 1,451 women with breast cancer contributed to the present analyses, including 1,347 Black women from Eastern (Zambia, Uganda), Southern (Namibia), and Western (Nigeria) and 104 non-Black women from Namibia. Relative to non-Black Namibians, Black women were, on average, diagnosed at a later stage, younger at diagnosis, more likely to live in a rural area, and had lower formal educational/literacy levels and lower socioeconomic profiles (Table 1). HIV prevalence was higher in Zambian, Ugandan, and Namibian Black women (ranging from 11 to $15 \%$ ) than in Nigerian and Namibian non-Black women (3\%). Belief in traditional medicine was highest in Zambia and Uganda (37-38\%) and lowest in Namibia non-Black women (7\%), while spiritual medicine beliefs were most common in Zambia (94\%) and less common in Uganda (48\%).

\section{Familiarity with breast cancer, its curability, and risk factors}

Almost none of the Namibian non-Black women had not previously heard of breast cancer, but one in seven Zambian and Namibian (non-black), and one in five Ugandan and Nigerian women had not (Table 2). Among women who had previously heard of breast cancer, the main source of their information was friends and family (35\%), the radio (16\%), the community (15\%), or health professionals (14\%); however, the sources varied across groups. For instance, written media were reported as the single main source by $27 \%$ of Namibian non-Black women (the most literate group) but by $<2 \%$ in Zambia, Uganda and Nigeria. The relative importance of radio and television varied from setting to setting, and the church was reported as a lesser source of information across all five population groups. Breast cancer cure awareness was much lower than general breast cancer awareness: overall, $53 \%$ believed it could be cured, but again with marked between-population differences (Table 2). Less than $40 \%$ of women in Uganda and Nigeria believed cure was possible compared to 60-75\% in Zambia/Namibia black and to the majority of Namibian non-Black women (98\%); $40 \%$ of women believed breast cancer was common.

Concerning knowledge of risk factors, 28\% (range $10-85 \%$ ) knew that the disease can be inherited, 26\% (range $17-61 \%$ ) knew that lifestyle could be a factor, and $18 \%$ (range 9-68) knew that risk of the disease increased with age (Table 2). Between 49 and $68 \%$ of Black women in each one of the four countries, and only $5 \%$ of non-Black Namibians, were unable to recognize at least one of these three risk factors (Table 2; Fig. 1). However, while Namibian women had the greatest proportions of correct risk factor information, they also believed in incorrect 'myths,' including injuries to the breast (over $40 \%$ of Namibian non-Black women) and infections (almost one quarter of Namibian Black women, Fig. 1). Some Namibian black, Ugandan, and Nigerian women also reported a curse or spiritual attack as causes of the disease. Unprompted causes specified by women were mobile phones; the use of contraceptives; and wearing illfitting or second hand bras.

The most frequent breast cancer symptom experienced by women (Table 3) was a lump in the breast $(87 \%)$, followed by pain (27\%), and swelling in the armpit (15\%). Overall, $10 \%$ (range 3-35\%) of women interpreted their symptom as cancer, and one-third as a breast lump (13-42\%). 20\% were worried but did not know what their symptom was, $20 \%$ felt that it was nothing to worry about, and $10 \%$ each interpreted it as an infection (1-23\%) or blocked milk duct (5-11\%). 
Table 2 Breast cancer awareness at baseline (breast cancer diagnosis) by population group within the ABC-DO cohort

\begin{tabular}{|c|c|c|c|c|c|c|c|}
\hline & \multicolumn{7}{|c|}{ Population group } \\
\hline & Zambia & Uganda & Nigeria & Namibia Black & Namibia non-Black ${ }^{\mathrm{a}}$ & Total & $p^{b}$ \\
\hline & $n=123$ & $n=428$ & $n=398$ & $n=398$ & $n=104$ & $n=1,451$ & \\
\hline & $N(\%)$ & $N(\%)$ & $N(\%)$ & $N(\%)$ & $N(\%)$ & $N(\%)$ & \\
\hline \multicolumn{8}{|c|}{ Familiarity with BC and its outcome } \\
\hline \multicolumn{8}{|l|}{ Have you ever heard about BC? } \\
\hline Yes & $105(85)$ & $338(79)$ & $304(76)$ & $335(84)$ & $103(99)$ & $1,185(82)$ & \\
\hline No/not sure & $18(15)$ & $90(21)$ & $94(24)$ & $63(16)$ & $1(1)$ & $266(18)$ & $<0.01$ \\
\hline \multicolumn{8}{|c|}{ Single main source of information about $\mathrm{BC}^{\mathrm{c}}$} \\
\hline Friends/relatives & $39(37)$ & $116(34)$ & $172(57)$ & $63(19)$ & $28(27)$ & $418(35)$ & \\
\hline Community & $23(22)$ & $80(24)$ & $36(12)$ & $36(11)$ & $7(7)$ & $182(15)$ & \\
\hline Radio & $3(3)$ & $71(21)$ & $8(3)$ & $97(29)$ & $14(14)$ & $193(16)$ & \\
\hline TV & $15(14)$ & $21(6)$ & $13(4)$ & $52(16)$ & $15(15)$ & $116(10)$ & \\
\hline Magazine & - & $2(1)$ & $2(1)$ & $20(6)$ & $28(27)$ & $52(4)$ & \\
\hline Dr/nurse & $23(22)$ & $29(9)$ & $56(18)$ & $56(17)$ & $6(6)$ & $170(14)$ & \\
\hline Church & $2(2)$ & $3(1)$ & $5(2)$ & - & $1(1)$ & $11(1)$ & \\
\hline Other $^{\mathrm{d}}$ & - & $16(5)$ & $12(4)$ & $11(3)$ & $4(4)$ & $43(4)$ & $<0.01$ \\
\hline \multicolumn{8}{|c|}{ Have you known anybody who has had BC? } \\
\hline Yes & $30(24)$ & $209(49)$ & $185(46)$ & $187(47)$ & $76(73)$ & $687(47)$ & \\
\hline No/not sure & $93(76)$ & $219(51)$ & $213(54)$ & $211(53)$ & $28(27)$ & $764(53)$ & $<0.01$ \\
\hline \multicolumn{8}{|l|}{ How common is BC? } \\
\hline $\begin{array}{l}\text { A frequent or most common } \\
\text { cancer (vs. rare/not sure) }\end{array}$ & $46(37)$ & $159(37)$ & $71(18)$ & $210(53)$ & $89(86)$ & $575(40)$ & $<0.01$ \\
\hline \multicolumn{8}{|l|}{ Belief $\mathrm{BC}$ is curable } \\
\hline Yes & $75(61)$ & $166(39)$ & $127(32)$ & $297(75)$ & $102(98)$ & $767(53)$ & \\
\hline No/not sure & $48(39)$ & $262(61)$ & $271(68)$ & $101(25)$ & $2(2)$ & $684(47)$ & $<0.01$ \\
\hline \multicolumn{8}{|c|}{ Knowledge of breast cancer risk factors: do you believe the following may cause BC? } \\
\hline \multicolumn{8}{|l|}{ Lifestyle, e.g., alcohol and diet } \\
\hline Yes & $21(17)$ & $74(17)$ & $105(26)$ & $117(29)$ & $63(61)$ & $380(26)$ & \\
\hline No/not sure & $102(83)$ & $354(83)$ & $293(74)$ & $281(71)$ & $41(39)$ & $1,071(74)$ & $<0.01$ \\
\hline \multicolumn{8}{|l|}{ Aging (“getting older”) } \\
\hline Yes & $11(9)$ & $53(12)$ & $11(3)$ & $120(30)$ & $71(68)$ & $266(18)$ & \\
\hline No/not sure & $112(91)$ & $375(88)$ & $387(97)$ & $278(70)$ & $33(32)$ & $1,185(82)$ & $<0.01$ \\
\hline \multicolumn{8}{|c|}{ Family history ("having other family members with BC") } \\
\hline Yes & $12(10)$ & $84(20)$ & $69(17)$ & $157(39)$ & $88(85)$ & $410(28)$ & \\
\hline No/not sure & $111(90)$ & $344(80)$ & $329(83)$ & $241(61)$ & $16(15)$ & $1,041(72)$ & $<0.01$ \\
\hline \multicolumn{8}{|c|}{ Knowledge of at least one cause above } \\
\hline Yes & $39(32)$ & $156(36)$ & $139(35)$ & $203(51)$ & $99(95)$ & $636(44)$ & \\
\hline No & $84(68)$ & $272(64)$ & $259(65)$ & $195(49)$ & $5(5)$ & $815(56)$ & $<0.01$ \\
\hline
\end{tabular}

$B C$ breast cancer

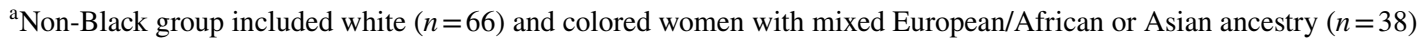

${ }^{\mathrm{b}} p$ value for difference in proportions between population groups, chi-squared test

${ }^{\mathrm{c}}$ Among women who had heard of BC

${ }^{\mathrm{d}}$ The more frequent other sources listed include own profession $(n=13)$, hospital/clinic/health workers $(n=8)$, multiple sources $(n=3)$

\section{Associations with breast cancer awareness}

Figures 2 and 3 show associations with lack of breast cancer: awareness (Fig. 2A), curability awareness (Fig. 2B), risk factor knowledge (Fig. 3A), and initial symptom recognition (Fig. 3B). Most associations were consistent across the four awareness indicators. Poor socioeconomic conditions such as low educational level, unskilled work, and low SEP 


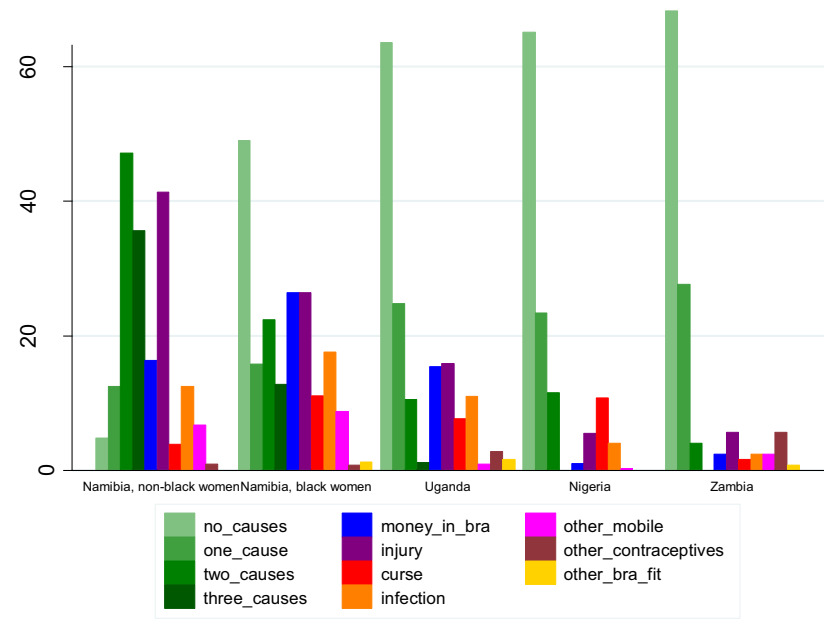

Fig. 1 Proportion of women with belief in established (green) and misconceived (other colors) risk factors for breast cancer by population group within the $\mathrm{ABC}-\mathrm{DO}$ cohort. (Color figure online) were strongly associated with less awareness. For instance, unskilled work was strongly associated with not having heard of breast cancer (OR 3.37, 95\% CI 2.17-5.23), believing that it is incurable (OR 2.43, 95\% CI 1.81-3.26), and not recognizing a breast lump symptom (OR $1.85,95 \% \mathrm{CI}$ 1.41-2.43), although with some evidence of between-country heterogeneity in the estimates $\left(I^{2}>50 \%\right.$ for all). These results were not materially altered by multiple-adjustment for age, marital status, residence, HIV status, comorbidity, and belief in spiritual medicine (not in tables). For example, less educated women were more likely to have never heard of breast cancer (age-adjusted OR 2.49; multiple-adjusted OR 2.30) and to think it incurable (age-adjusted OR 2.41; multiple-adjusted OR 2.23).

Age (10 year increase) and rural residence were also associated with lack of any breast cancer awareness (OR $1.44,95 \%$ CI $1.30-1.59$ and $1.48,95 \%$ CI $1.07-2.05$, respectively), lack of cure awareness (OR 1.25, 95\% CI 1.15-1.37 and $1.51,95 \%$ CI 1.17-1.95), and less knowledge of risk factors (OR 1.11, 95\% CI 1.03-1.20 and $1.83,95 \%$ CI 1.44-2.32), although again with evidence of

Table 3 Self-reported first symptoms experienced by women with breast cancer and how they were interpreted by population group within the ABC-DO cohort

\begin{tabular}{|c|c|c|c|c|c|c|c|}
\hline \multirow[t]{4}{*}{ Variable } & \multicolumn{7}{|c|}{ Population group } \\
\hline & Zambia & Uganda & Nigeria & Namibia Black & $\begin{array}{l}\text { Namibia non- } \\
\text { Black }^{\mathrm{a}}\end{array}$ & Total & $p^{b}$ \\
\hline & $n=123$ & $n=428$ & $n=398$ & $n=398$ & $n=104$ & $n=1,451$ & \\
\hline & $N(\%)$ & $N(\%)$ & $N(\%)$ & $N(\%)$ & $N(\%)$ & $N(\%)$ & \\
\hline \multicolumn{8}{|l|}{ Reported first symptom $^{c}$} \\
\hline Lump or thickening of breast & $113(92)$ & $322(76)$ & $372(94)$ & $355(89)$ & $87(85)$ & $1,249(87)$ & $<0.01$ \\
\hline Pain in the breast & $28(23)$ & $45(11)$ & $197(50)$ & $104(26)$ & $10(10)$ & $384(27)$ & $<0.01$ \\
\hline Dimpling of the skin & $4(3)$ & $15(4)$ & $30(8)$ & $63(16)$ & $9(9)$ & $121(8)$ & $<0.01$ \\
\hline Fluid coming from nipple & $13(11)$ & $12(3)$ & $43(11)$ & $59(15)$ & $6(6)$ & $133(9)$ & $<0.01$ \\
\hline Swelling or lump in armpit & $4(3)$ & $34(8)$ & $102(26)$ & $65(16)$ & $10(10)$ & $215(15)$ & $<0.01$ \\
\hline Change in the shape of breast & $8(7)$ & $8(2)$ & $40(10)$ & $45(11)$ & $9(9)$ & $110(8)$ & $<0.01$ \\
\hline Other & $8(7)$ & $83(20)$ & $3(1)$ & $54(14)$ & $20(19)$ & $168(12)$ & $<0.01$ \\
\hline \multicolumn{8}{|l|}{ Symptom interpretation $^{\mathrm{d}}$} \\
\hline \multicolumn{8}{|l|}{ Breast lump and cancer } \\
\hline Cancer & $5(4)$ & $42(10)$ & $11(3)$ & $57(14)$ & $35(35)$ & $150(10)$ & \\
\hline Breast lump & $16(13)$ & $85(20)$ & $166(42)$ & $93(24)$ & $31(31)$ & $391(27)$ & \\
\hline \multicolumn{8}{|l|}{ Other interpretations } \\
\hline Blocked milk duct & $10(8)$ & $41(10)$ & $18(5)$ & $43(11)$ & $10(10)$ & $122(8)$ & \\
\hline Worried but did not know & $34(28)$ & $40(9)$ & $104(26)$ & $76(19)$ & $8(8)$ & $262(18)$ & \\
\hline Nothing to worry about & $21(17)$ & $84(20)$ & $60(15)$ & $92(23)$ & $9(9)$ & $266(18)$ & \\
\hline Infection & $28(23)$ & $83(19)$ & $16(4)$ & $24(6)$ & $1(1)$ & $152(11)$ & \\
\hline Other & $9(7)$ & $53(12)$ & $23(6)$ & $11(3)$ & $7(7)$ & $103(7)$ & \\
\hline
\end{tabular}

${ }^{a}$ Non-Black group included white $(n=66)$ and colored women with mixed European/African or Asian ancestry $(n=38)$

${ }^{\mathrm{b}} p$ value for difference in proportions between population groups, chi-squared test

${ }^{\mathrm{c}}$ Symptoms were not mutually exclusive

${ }^{\mathrm{d}}$ Single select question 
(A)

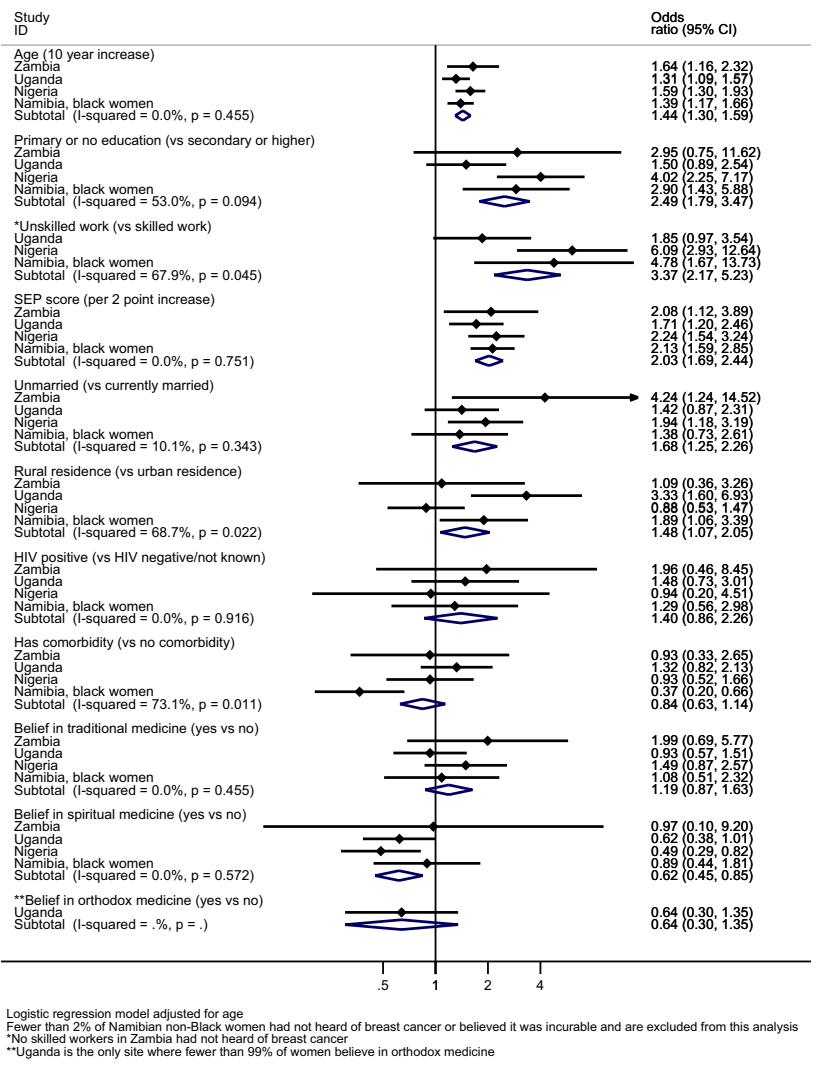

(B)

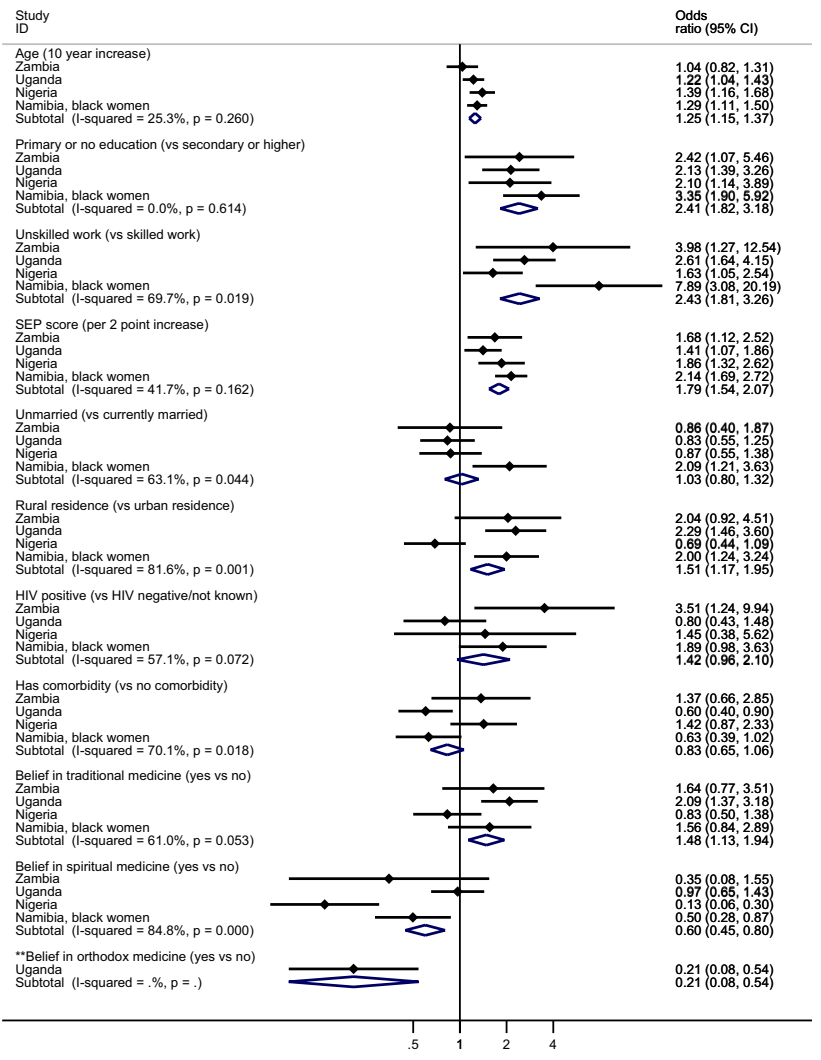

Fig. 2 Odds of women never having heard of breast cancer $(\mathbf{A})$ and odds of holding the belief that breast cancer is incurable (B) by population group within the ABC-DO cohort

between-country heterogeneity. Unmarried women were more likely to have never heard of breast cancer (OR 1.68, 95\% CI 1.25-2.26), have less knowledge of risk factors (OR $1.27,95 \%$ CI 1.02-1.57), and to not recognize their breast lump symptom (OR 1.31, 95\% CI 1.03-1.68), although not in every setting. HIV-positive ( $9 \%$ of the cohort) women in Zambia (OR 3.51, 95\% CI 1.24-9.94) and Namibian Black women (OR 1.89, 95\% CI 0.98-3.63) were more likely to believe breast cancer is incurable, while women in Uganda (OR 0.60, 95\% CI 0.40-0.90) and Namibian Black women (OR $0.63,95 \%$ CI 0.39-1.02) with comorbidities were less likely to think it is incurable, and these two groups also had greater knowledge of risk factors. Among Namibian Black women, HIV-positive women had less knowledge of breast cancer risk factors (OR 2.04, 95\% CI 1.16-3.60) than HIV negative.

Belief in traditional medicine was associated lower breast cancer cure awareness (OR 1.48, 95\% CI 1.13-1.94 for no awareness), but not with other awareness measures. In contrast, belief in spiritual medicine was associated with greater general breast cancer awareness (OR 0.62, 95\% CI 0.45-0.85 for no awareness) and greater cure awareness (OR 0.60, 95\% CI $0.45-0.80$ for no cure awareness) but lower risk factor knowledge and symptom recognition (OR 1.63, 95\% CI 1.23-2.16 for no recognition); however, the magnitude of these associations was not always consistent across population groups ( $I^{2}$ range $\left.0-85 \%\right)$. Belief in orthodox (western) medicine were estimated for Uganda only, and were associated with greater cure awareness (OR $0.21,95 \% \mathrm{CI}$ 0.08-0.54 for no cure awareness); however they had lower symptom recognition (OR 2.78, 95\% CI 1.32-5.84 for no recognition).

\section{Discussion}

\section{Main findings}

This study identified characteristics associated with poor breast cancer awareness including those relevant across the diverse study population groups as well as those specific to a particular setting. Having low SEP indicators, based on literacy, education, and employment, were consistently associated with lower breast cancer awareness overall, of its risk factors, and potential cure. The study additionally provided valuable information on where different population groups 
(A)

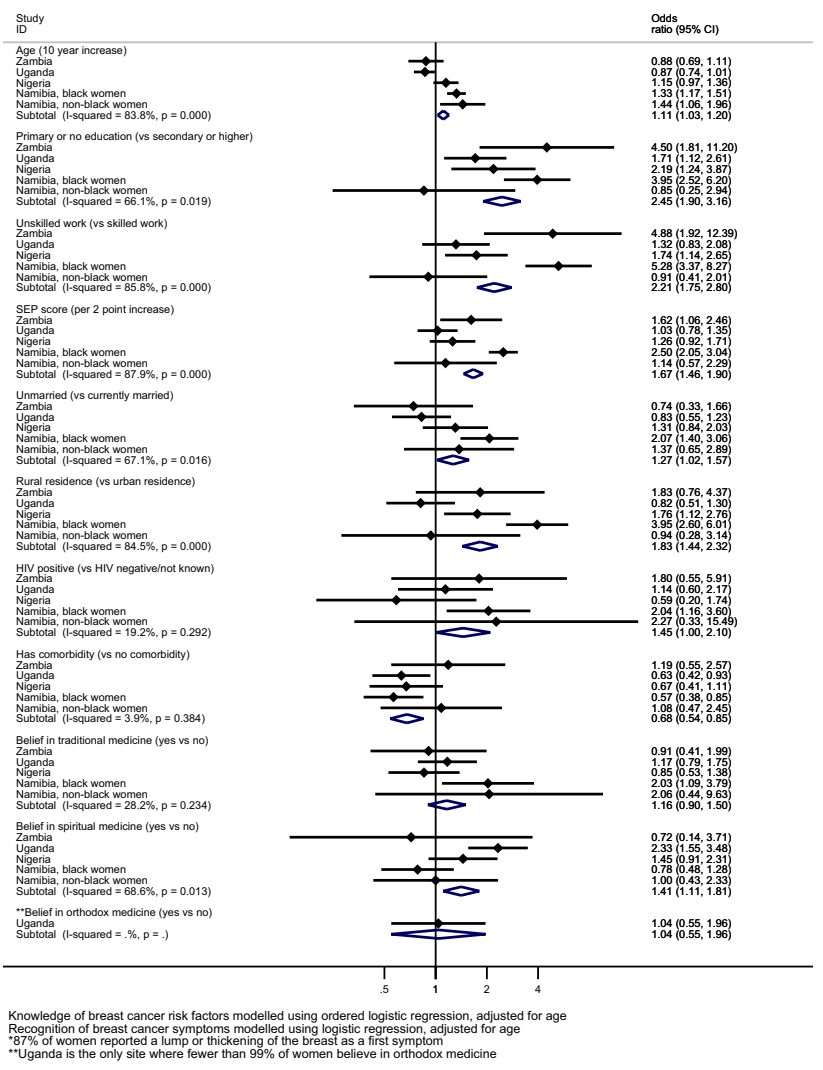

(B)

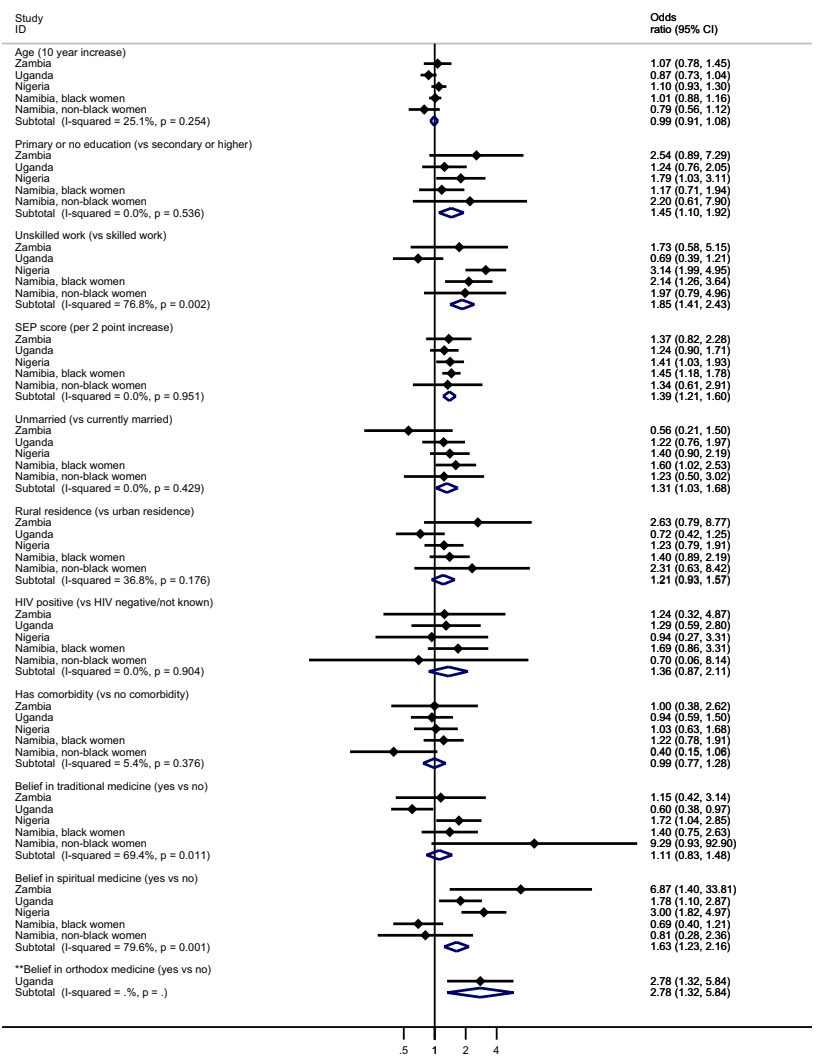

Fig. 3 Odds of women having less knowledge of breast cancer risk factors (A) and odds of women not recognizing breast cancer symptoms (B) by population group within the ABC-DO cohort

source their breast cancer information, suggesting appropriate and underused mediums to reach specific groups. The study further demonstrated that even among women who had relatively good familiarity of breast cancer risk factors, beliefs in incorrect and misleading myths of risk factors were highly prevalent.

\section{Comparisons with other studies}

Many of the findings are consistent with previous research available. Large ethnic variations in cancer awareness have been documented in developed countries; in the UK, for example, first-generation black African women had among the lowest breast cancer awareness and had poor, if any, awareness of specific breast cancer symptoms compared with other ethnic groups [23]. Despite breast cancer being among the top two most common cancers in women in most SSA countries [1], awareness of the disease remains low across most of the region [24, 25], and there is a paucity of information around breast cancer awareness [21, 22, 26-28]. A south Nigerian urban community-based survey specifically assessed knowledge of aging and inheritability and found that 25 and $26 \%$ of its participants, respectively, were aware of these two risk factors for breast cancer [11]. Similar proportions of participants (26 and 16\%, respectively) were reported in an urban Tanzanian outpatient study [21]. The findings from these two studies are consistent with those from the present study (18 and $28 \%$, respectively, for all population groups combined). The south Nigerian study further found that $41 \%$ of women believed that it was curable if detected early [11]. Another population-based study in northern Nigeria found that $68 \%$ of their participants thought breast cancer is curable [8]. While the estimates from these two studies are roughly in line with the overall estimate of $53 \%$ found in the ABC-DO study, they are, nevertheless, higher than the $32 \%$ seen in the ABC-DO Nigerian settings located in the south of the country; thus, highlighting the need to consider setting-specific variations in awareness and beliefs and possibility of lower awareness outside of major cities. Familiarity with breast cancer symptoms has previously been found to be poor among SSA populations; a door-to-door survey in a South African township found $>75 \%$ regarded a lump or thickening in the breast as serious, yet only $13 \%$ of the group associated these signs with cancer [12], similar to the present study. Particularly in line with our findings, associations between low breast cancer 
awareness and more deprived or less educated women have been shown previously in SSA [11, 12, 27], as has a relationship between working in a professional employment category and increased breast cancer knowledge [11].

\section{Strengths and limitations}

The major strengths of the study were the common methodology used across the study settings, the high participation rate $(\sim 99 \%)$, and the high quality and degree of completeness of the baseline questionnaire data, the collection of which was aided by m-Health implementation [17]. Limitations of the study included the fact that the study population comprised recently diagnosed breast cancer patients, primarily from tertiary hospital settings, whose awareness levels may differ to that of the general population. Furthermore, with a prolonged diagnostic period in most settings in SSA, some women may have been already informed or aware of their disease status, some more prior to the baseline interview. Nevertheless, it could be surmised that, if anything, breast cancer patients would potentially have increased awareness compared to the general population.

\section{Implications}

This study demonstrated clear differences in breast cancer awareness and beliefs across different settings, highlighting the very real need for context-specific awareness programmes in the SSA region. There were clear associations between SEP indicators and breast cancer awareness (education/literacy, employment, SEP) stressing the importance of reaching specific disadvantaged groups. This includes nonliterate women, thereby reinforcing the need for awareness programmes to also be appropriate for audiences without reading and writing abilities. There is a very real detrimental flow-on effect to an already disadvantaged population, as low awareness of signs and symptoms of cancer, combined with negative beliefs, leads to late help-seeking behavior and consequently late diagnosis [4, 29, 30]. Interpretation of breast cancer risks, and symptoms, is a key determining factor in the pre-diagnostic pathway for seeking care.

A relatively high proportion of women in this study were aged 50 or less and it was common to attribute their symptom to being a blocked milk duct; therefore, in these settings it would be beneficial to utilize the contact with the health system around the time of pregnancy to increase breast cancer awareness. Similarly, and as advocated for other NCDs, contacts with the successful HIV platform can be used to educate HIV-positive women who had lower breast cancer awareness (in contrast with the trend among women with other comorbid conditions).

Belief in myths and incorrect information surrounding breast cancer was widespread, especially among those also holding correct knowledge. It is important to dispel myths and belief in incorrect risks and causes of breast cancer, particularly relating to harmful beliefs such as contraceptive use, breast feeding, or spiritual attacks causing breast cancer. There is stigma surrounding many aspects of breast cancer in SSA, often related to traditional superstitions including such things as evil spirits [31]; being God's will and reliance on divine intervention [21, 22]; or the woman herself being evil, being a financial burden, no longer being a real woman [22]; and even with regard to recovery which can be viewed as 'witchcraft prowess.' Consequently, women with breast cancer can be rejected by friends and family, and even their daughters/sisters can be seen as 'poor marriage investment' (Anele, personal communication, 6 September 2017). To address these types of stigma, and because in these settings women's main source of breast cancer information was reported to be from friends and family, it is important that correct information is conveyed to the whole community so that what is passed on to women is correct. Communitywide awareness programmes should be considered a priority, and while there have been valuable steps in this area in SSA $[31,32]$, reliable baseline knowledge such as this, is needed in order to design and implement the most effective community programmes.

\section{Conclusion}

This study has identified groups of women across SSA with low awareness and familiarity of breast cancer, its risks, and symptoms. It has further highlighted which demographic associations with breast cancer familiarity are context-specific, and those that are more general. This is a key step forward to aid implementation of much needed awareness programmes in the region. It would be beneficial for such programmes to be tailored based on the context-specific misconceptions of breast cancer, its risks, symptoms, and outlook relevant to each community setting in SSA.

Acknowledgments The authors thank the women who participated in this study. They also thank the dedicated team of research assistants, notably Johanna Pontac, Allen Naamala, Agnes Kaggwa, Anne Nteziryayo, Teopista Nakazibwe, Chris Sule Oyamienlen, Kingsley Iwuoha, Esther Ezeigbo, Mildred Lusaka, and Mirriam Mudolo.

Funding ABC-DO is supported by the Susan G Komen for the Cure Foundation (IIR 13264158 to IARC and as part of "Implementing breast cancer care efficiency in Zambia through specialized health provider training and m-health evaluation of patient outcomes" for the Zambian site) and by IARC.

\section{Compliance with ethical standards}

Conflict of interest The authors declare no potential conflicts of interest. 


\section{References}

1. Ferlay J, Soerjomataram I, Dikshit R et al (2015) Cancer incidence and mortality worldwide: sources, methods and major patterns in GLOBOCAN 2012. Int J Cancer 136:E359-E386

2. Ervik M, Lam F, Ferlay J, Mery L, Soerjomataram I, Bray F (2016) Cancer today. International Agency for Research on Cancer, Lyon. Cancer today. http://gco.iarc.fr/today. Accessed 26 July 2017

3. Jedy-Agba E, McCormack V, Adebamowo C, Dos-Santos-Silva I (2016) Stage at diagnosis of breast cancer in sub-Saharan Africa: a systematic review and meta-analysis. Lancet Glob Health 4:e923-e935

4. Richards MA (2009) The national awareness and early diagnosis initiative in England: assembling the evidence. Br J Cancer 101:S1-S4

5. Whitaker KL, Scott SE, Wardle J (2015) Applying symptom appraisal models to understand sociodemographic differences in responses to possible cancer symptoms: a research agenda. $\mathrm{Br} \mathrm{J}$ Cancer 112:S27-S34

6. Mbuka-Ongona D, Tumbo JM (2013) Knowledge about breast cancer and reasons for late presentation by cancer patients seen at Princess Marina Hospital, Gaborone, Botswana. Afr J Prim Health Care Fam Med 5:465

7. Ibrahim NA, Oludara MA (2012) Socio-demographic factors and reasons associated with delay in breast cancer presentation: a study in Nigerian women. The Breast 21:416-418

8. Azubuike SO, Celestina UO (2015) Breast cancer: the perspective of northern Nigerian Women. Int J Prev Med 6:130

9. Pruitt L, Mumuni T, Raikhel E et al (2015) Social barriers to diagnosis and treatment of breast cancer in patients presenting at a teaching hospital in Ibadan, Nigeria. Glob Public Health 10:331-344

10. Otieno ES, Micheni JN, Kimende SK, Mutai KK (2010) Delayed presentation of breast cancer patients. East Afr Med J 87:147-150

11. Okobia MN, Bunker CH, Okonofua FE, Osime U (2006) Knowledge, attitude and practice of Nigerian women towards breast cancer: a cross-sectional study. World J Surg Oncol 4:11-11

12. Maree JE, Wright SCD (2010) How would early detection be possible? An enquiry into cancer related knowledge, understanding and health seeking behaviour of urban black women in Tshwane, South Africa. Eur J Oncol Nurs 14:190-196

13. Clegg-Lamptey J, Dakubo J, Attobra YN (2009) Why do breast cancer patients report late or abscond during treatment in Ghana? A pilot study. Ghana Med J 43:127-131

14. Espina C, McKenzie F, dos Santos-Silva I (2017) Delayed presentation and diagnosis of breast cancer in African women: a systematic review. Ann Epidemiol 27:659-671

15. Westerlund D (2006) African indigenous religions and disease causation. Brill NV, Leiden

16. WHO (2017) Guide to cancer early diagnosis. World Health Organization, Geneva

17. McKenzie F, Zietsman A, Galukande $M$ et al (2016) African Breast Cancer-Disparities in Outcomes (ABC-DO): protocol of a multicountry mobile health prospective study of breast cancer survival in sub-Saharan Africa. BMJ Open. https://doi. org/10.1136/bmjopen-2016-011390

18. McKenzie F, Zietsman A, Galukande M et al (2017) Drivers of advanced stage at breast cancer diagnosis in the multi-country African Breast Cancer-Disparities in Outcomes (ABC-DO) study. Int J Cancer 142:1568-1579

19. Key TJ, Verkasalo PK, Banks E (2001) Epidemiology of breast cancer. Lancet Oncol 2:133-140

20. World Cancer Research Fund International/American Institute for Cancer Research (2017) Continuous update project report: diet, nutrition, physical activity and breast cancer. https://wcrf. org/breast-cancer-2017. Accessed 2 Sept 2017

21. Morse EP, Maegga B, Joseph G, Miesfeldt S (2014) Breast cancer knowledge, beliefs, and screening practices among women seeking care at district hospitals in Dar es Salaam, Tanzania. Breast Cancer 8:73-79

22. Opoku SY, Benwell M, Yarney J (2012) Knowledge, attitudes, beliefs, behaviour and breast cancer screening practices in Ghana, West Africa. Pan Afr Med J 11:28

23. Niksic M, Rachet B, Warburton FG, Forbes LJL (2016) Ethnic differences in cancer symptom awareness and barriers to seeking medical help in England. Br J Cancer 115:136-144

24. Moyo S (2017) Men's knowledge about prostate cancer: a case study of rural Mhondoro-Ngezi, Kadoma District, Zimbabwe. Eur J Cancer Care 26:e12493

25. Zeitoun O, Shemesh N (2017) The level of breast and cervical cancer awareness among women in a rural area of South Africa. S Afr J Surg 55:47

26. Akuoko CP, Armah E, Sarpong T, Quansah DY, Amankwaa I, Boateng D (2017) Barriers to early presentation and diagnosis of breast cancer among African women living in sub-Saharan Africa. PLoS ONE 12:e0171024

27. Akhigbe AO, Omuemu VO (2009) Knowledge, attitudes and practice of breast cancer screening among female health workers in a Nigerian urban city. BMC Cancer 9:203-203

28. Akuoko CP (2017) Quality of breast cancer information on the internet by African Organizations: an appraisal. Int J Breast Cancer 2017:2026979

29. Macleod U, Mitchell ED, Burgess C, Macdonald S, Ramirez AJ (0000) Risk factors for delayed presentation and referral of symptomatic cancer: evidence for common cancers. Br J Cancer 101:S92-S101

30. Simon AE, Waller J, Robb K, Wardle J (2010) Patient delay in presentation of possible cancer symptoms: the contribution of knowledge and attitudes in a UK population sample. Cancer Epidemiol Biomark Prev 19:2272-2277

31. Mena M, Wiafe-Addai B, Sauvaget C et al (2014) Evaluation of the impact of a breast cancer awareness program in rural Ghana: a cross-sectional survey. Int J Cancer 134:913-924

32. Abuidris DO, Elsheikh A, Ali M et al (2013) Breast-cancer screening with trained volunteers in a rural area of Sudan: a pilot study. Lancet Oncol 14:363-370 